\title{
Evolutionary dynamics of the main-stem longitudinal profiles of ten kongdui basins within Inner Mongolia, China
}

\author{
GU Zhenkui ${ }^{1,2}$, SHI Changxing ${ }^{1}$, PENG Jie ${ }^{3}$ \\ 1. Key Laboratory of Water Cycle and Related Land Surface Processes, Institute of Geographic Sciences and \\ Natural Resources Research, CAS, Beijing 100101, China; \\ 2. University of Chinese Academy of Sciences, Beijing 100049, China; \\ 3. China University of Geosciences, Beijing 100083, China
}

\begin{abstract}
The longitudinal profiles of main streams of ten kongdui basins within Inner Mongolian Autonomous Region of China were characterized in this study by analyzing a series of quantitative indexes that are relevant to tectonic activity and river action, and by establishing a series of multiple regression models. The results reveal that all longitudinal profiles are concave in shape, with a range of concavity between 1.1 and 3.1 , increasing from west to east. Data also show that the concavity of the profiles is significantly negatively correlated with profile length, altitude difference, average altitude, drainage area and sediment load of the basins. Analysis reveals that kongdui basins have suffered from moderate-to-weak tectonic activity over time, again characterized by a west-to-east weakening trend. Stream power also varies along the main channels of the ten kongdui basins; average values in each case fall between $0.8 \mathrm{~W} / \mathrm{m}$ and $8.4 \mathrm{~W} / \mathrm{m}$, generally higher within the middle reaches. This decreasing trend in stream power within the lower reaches of kongdui basins might provide one key explanation for sedimentation there. Data also show that the average stream power in western and central basins tends to be higher than that in eastern examples, even though both the highest and the lowest values are seen within two middle ones. This analysis shows that the longitudinal profile concavity values are mainly controlled by tectonic activity and that the effect of river action is insignificant.
\end{abstract}

Keywords: longitudinal profiles; concavity; tectonic activity; stream power; multiple regression models

\section{Introduction}

River channels are the most important conduits for the transport of material and energy throughout geomorphological evolution. In the long term evolutionary processes, changes in sediment within main channels as well as in stream profile and surface morphology all occur

Received: 2017-10-25 Accepted: 2018-02-22

Foundation: National Natural Science Foundation of China, No.41671004, No.41371036

Author: Gu Zhenkui, PhD, specialized in fluvial geomorphology. E-mail: bygzk853@126.com

"Corresponding author: Shi Changxing, $\mathrm{PhD}$ and Professor, specialized in fluvial geomorphology and sediment dynamics. E-mail: shicx@igsnrr.ac.cn 
in response to spatial and temporal variations in tectonic activity, lithologic characteristics, and climate. Such changes are indicative of morphological evolutionary characteristics (e.g., Rãdoane et al., 2003; Font et al., 2010; Pérez-Peña et al., 2010; Ambili and Narayana, 2014). As one basic channel element of river basins, the longitudinal profiles of their main streams are created by the collective influence of both internal and external forces; understanding the development of such features is a key research topic within the fields of tectonics and river geomorphology. A large range of studies have been carried out over the last few decades on the longitudinal profiles; the research methods currently applied to the analyses in this area include profile fitting via mathematical functions to assess evolutionary stage (e.g., Ohmori, 1991; Rãdoane et al., 2003) as well as quantitative parameter extraction to analyze the characteristics of basin tectonic activity (e.g., Font et al., 2010; Pérez-Peña et al., 2010; Mahmood and Gloaguen, 2012; Pan et al., 2015; Gao et al., 2016; Owono et al., 2016). The physical mechanisms that underline the evolution of longitudinal profiles have also been investigated by many scholars in recent years through utilizing stream power erosion models to pinpoint and explain the formation and changes of profile morphology (e.g., Snow and Slingerland, 1987; Hu et al., 2010; Miller et al., 2013; Ambili and Narayana, 2014; Gallen and Wegmann, 2017). A suite of geomorphic parameters in these models are applied to analyze the characteristics of longitudinal profiles, including length gradient (e.g., Font et al., 2010; Mahmood and Gloaguen, 2012) and steep indexes (e.g., Hu et al., 2010, 2014; Miller et al., 2013) as well as concavity values (e.g., Langbein, 1964; Jiang, 1987; Phillips et al, 2008); not only do these parameters describe the morphological features of longitudinal profiles, they are also indicative of the characteristics of tectonic and river activities. The characteristics of a single dynamic factor, either tectonic activity or river action, have often been evaluated in previous analyses, while the coupled dynamic structure of internal-external forces has usually been ignored (e.g., Rãdoane et al., 2003; Zhao et al., 2014; Dušan et al., 2017). Stream power erosion models often simultaneously encapsulate tectonic activity and river action (e.g., Snow and Slingerland, 1987; Font et al., 2010; Hu et al., 2010, 2014; Pérez-Peña et al., 2010) and include a number of empirical parameters that are often difficult to ascertain as they vary between different areas. Constant improvements in the accuracy of digital elevation models (DEMs) and in GIS technology over the last 20 years (e.g., Bergonse and Reis, 2015) have enabled the characteristics of tectonic and fluvial actions to be reliably described via quantitative indicators. These developments mean that uncertain empirical parameters can be discarded by establishing multiple regression models, and the dynamic mechanisms that underlie longitudinal profile evolution can be understood.

The section of the Yellow River within the Inner Mongolian Autonomous Region of China includes ten tributaries ("kongdui" in Mongolian). They are characterized by strong wind-fluvial interactive erosion as well as high floods and heavy sediment loads. The Yellow River itself is therefore also heavily influenced by huge input of sediments from these kongduis. Although scholars to date have studied sediment transport mechanisms (Xu, 2013; Yao et al., 2016), estimated sediment discharge (Lin et al., 2014), and analyzed the characteristics of wind-fluvial interactive erosion (Xu et al., 2014), little attention has so far been afforded to the dynamic mechanisms that underlie longitudinal profile evolution. The aim of this study is therefore to identify the main dynamic factors that have driven the longitudinal profiles to evolve by analyzing tectonic activity and river action characteristics and longitu- 
dinal profile morphological features.

\section{Study area}

The ten tributaries of the Yellow River in this region flow into the main channel from south-to-north (Figure 1). Identified from west-to-east (Table 1), they are the Maobula Kongdui (MBL), the Buersetai Kongdui (BES), the Heilaigou Kongdui (HLG), the Xiliugou Kongdui (XLG), the Hantaichuan Kongdui (HTC), the Haoqinghe Kongdui (HQH), the Hashilachuan Kongdui (HSL), the Muhuagou Kongdui (MHG), the Dongliugou Kongdui (DLG), and the Husitai Kongdui (HST). This study area experiences a temperate continental monsoonal climate and it is noteworthy that the morphological features of tributary basins were mainly formed during the Quaternary. The climate of this region is consistent with an arid grassland and semi-desert zone (Xu, 2013); annual average precipitation within western basins is about $250 \mathrm{~mm}$, gradually increasing to $350 \mathrm{~mm}$ in the east, while rainfall in July and August encompasses between $50 \%$ and $60 \%$ of the overall annual total. The upper reaches of the XLG and the HTC also experience frequent rainstorms (Lin et al., 2014); these basins mainly comprise two tectonic units, i.e., a downstream alluvial plain within the Hetao Basin that formed in the Cenozoic, and the upstream area on the Ordos Plateau. This latter region was also uplifted to a plateau within the Cenozoic and experienced several episodes of uplift during the Quaternary (Yue et al., 2007) with a current uplift rate between $1 \mathrm{~mm} / \mathrm{a}$ and 2.8 $\mathrm{mm} / \mathrm{a}$ (Deng et al., 1999). The basins have a maximum altitude of approximately $1,600 \mathrm{~m}$. The upstream basins are mainly underlain by gray-green and purple Mesozoic fluvial-lacustrine clastic rocks that have loose lithological structure and poor resistance to erosion (Yang et al., 2015), while their downstream counterparts are mainly covered by Quaternary alluvial deposits.

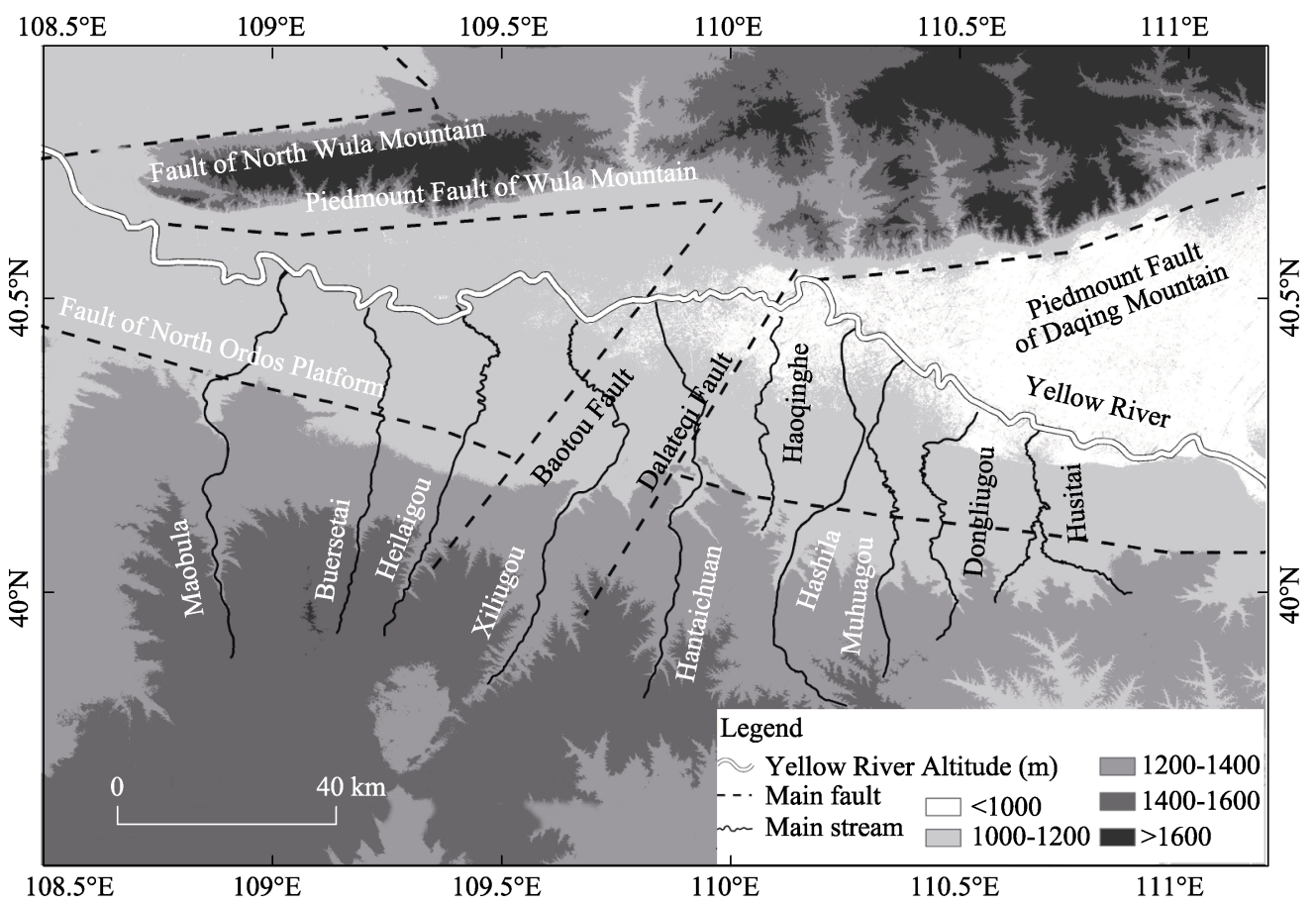

Figure 1 Map showing location of the tributaries (kongduis) 
Table 1 Kongdui landform elements and sediment yields

\begin{tabular}{ccccc}
\hline Kongdui & $\begin{array}{c}\text { Longitudinal profile } \\
\text { length }(\mathrm{km})\end{array}$ & $\begin{array}{c}\text { Altitude } \\
\text { difference }(\mathrm{m})\end{array}$ & $\begin{array}{c}\text { Drainage area } \\
\left(\mathrm{km}^{2}\right)\end{array}$ & $\begin{array}{c}\text { Sediment } \\
\text { yield }\left(10^{4} \mathrm{t} / \mathrm{yr}\right)^{*}\end{array}$ \\
\hline MBL & 101 & 501 & 1,261 & 439 \\
BES & 74 & 545 & 545 & 205 \\
HLG & 86 & 439 & 944 & 329 \\
XLG & 101 & 394 & 1,194 & 482 \\
HTC & 94 & 438 & 875 & 184 \\
HQH & 50 & 242 & 1,089 & 41 \\
HSL & 94 & 395 & 407 & 201 \\
MHG & 72 & 366 & 451 & 72 \\
DLG & 68 & 329 & 406 & 77 \\
HST & 60 & 268 & & 67 \\
\hline
\end{tabular}

$* \mathrm{Xu}(2014)$

\section{Methodology and data}

\subsection{Data}

The topographic data used in this study are derived from a SRTM 1 " DEM (http://earthexplorer.usgs.gov/) that has a spatial resolution of approximately $30 \mathrm{~m}$ and about a 5 m elevation error (Pipaud et al., 2015; Yu et al., 2017). Values for average annual rainfall within kongdui basins were generated by interpolating data recorded at meteorological stations across the study area (http://data.cma.cn) via the inverse distance weight method (IDW).

\subsection{Longitudinal profile concavity}

Based on Langbein's (1964) concavity index, longitudinal profile concavity index values were computed as follows:

$$
C I=S_{1} / S_{2}
$$

where $S_{1}$ and $S_{2}$ denote the areas of upper and lower sections, respectively, encapsulated by the longitudinal profile and the rectangular boundary (Figure 2). If $0<C I<1$ then the longitudinal profile is convex and prone to erosion. If $C I=1$, then the profile almost comprises a straight line and can be said to be in a transitional evolutionary phase. If $0>C I>1$, then the profile has a concave shape and can be said to be in an adjustment phase (Phillips et al., 2008). It is generally thought that the morphology of a longitudinal profile is related to both tectonic activity and river action within catchments where substrate is uniform. Thus, in order to obtain longitudinal profile concavity values, a number of basin

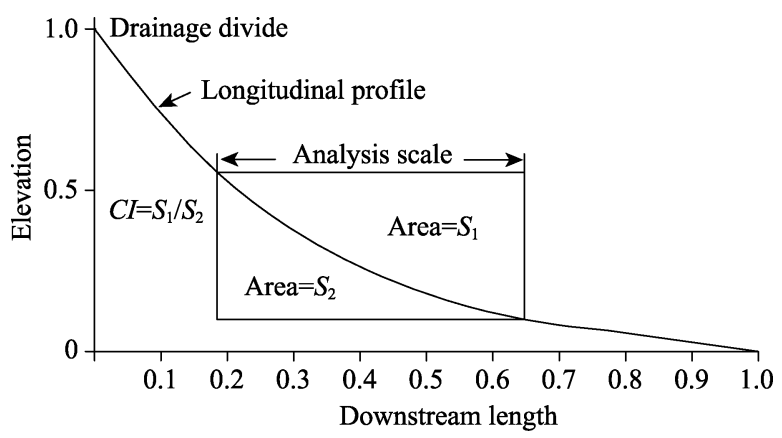

Figure 2 Sketch of definition of concavity index 
hydrological characteristics were analyzed using DEM data in the ArcGIS software platform following the processes shown in Figure 3.

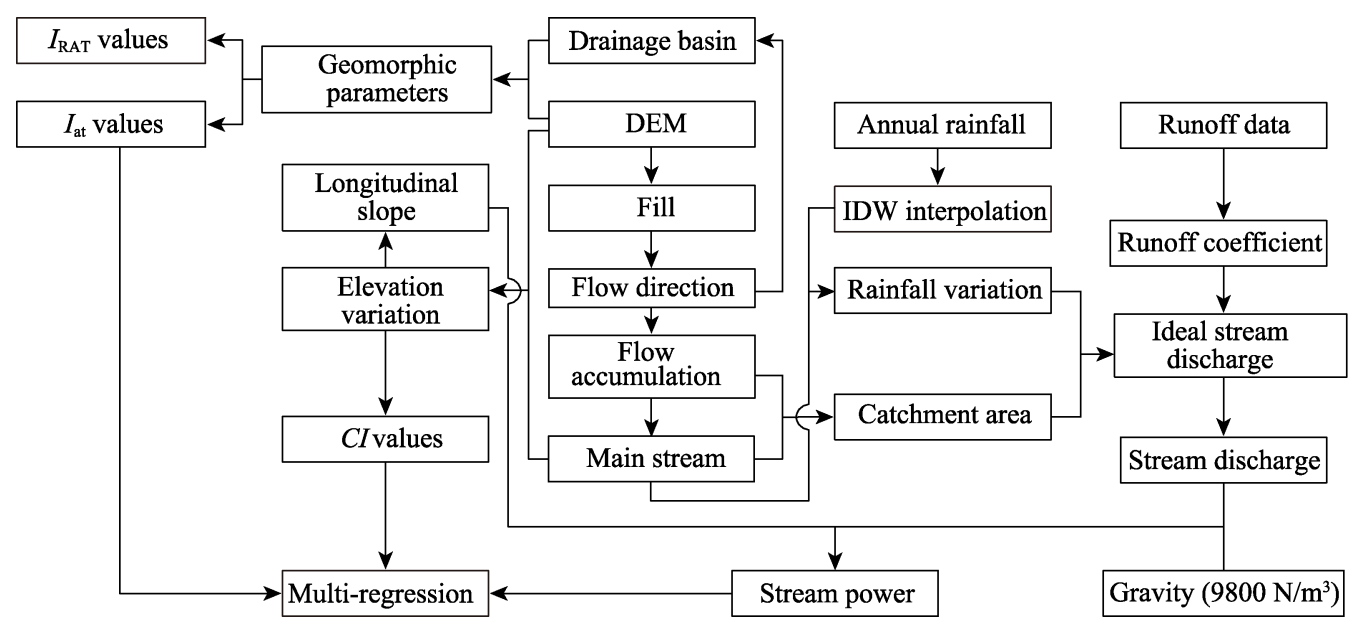

Figure 3 The processes followed to acquire parameters

\subsection{The intensity of tectonic activity}

The morphological characteristics of river longitudinal profiles are influenced by tectonic activity within basins, the intensity of which can be evaluated using a range of geomorphic indexes (e.g., Hamdouni, 2008; Gao et al., 2016; Owono et al., 2016). These include hypsometric integral $(H I)$, asymmetry factor $(A F)$, stream length gradient $(S L)$, basin shape $(B s)$, and valley floor width-to-height ( $V f)$ ratio; all of these measures were extracted from a DEM (Table 2).

The high, moderate, and low levels of tectonic activity for each geomorphic parameter are assigned 1, 2, and 3, respectively. The mean of level values of all geomorphic parameters is used as an index of relative tectonic activity $\left(I_{\mathrm{RAT}}\right)$ :

$$
I_{\mathrm{RAT}}=\frac{S_{H I}+S_{A F}+S_{S L}+S_{B s}+S_{V f}}{5}
$$

where $S$ denotes the level value and $I_{\text {RAT }}$ index outputs are generally divided into four classes, scaled between 1 and 4 . The four classes are $1.0 \leqslant I_{\mathrm{RAT}}<1.5,1.5 \leqslant I_{\mathrm{RAT}}<2.0$, $2.0 \leqslant I_{\mathrm{RAT}}<2.5$, and $2.5 \leqslant I_{\mathrm{RAT}}<3$, indicating intense, strong, moderate, and weak tectonic activities, respectively (e.g., Hamdouni et al., 2008; Altın, 2012; Mahmood and Gloaguen, 2012; Gao et al., 2016). As the index $I_{\text {RAT }}$ is calculated from the level values of geomorphic parameters, some information of tectonic activity intensity may lose in the conversion from continuous values to level ones. For avoiding this defect of $I_{\text {RAT }}$, we defined another index for relative tectonic activity. It is the index $I_{\text {at }}$, which is the mean of all normalized values of geomorphic indexes, as follows:

$$
I_{\text {at }}=\frac{N_{H I}+N_{|A F-50|}+N_{S L}+N_{B S}+N_{1 / V f}}{5}
$$

In this expression, $N$ denotes normalized values for geomorphic indexes (i.e., $H I$, $|A F-50|, S L, B s$, and $1 / V f)$ and ranges between zero and one. 
Table 2 The formulae used in this study to compute geomorphic parameters and corresponding threshold value interpretations

\begin{tabular}{|c|c|c|}
\hline Parameter & Formula & Threshold value interpretation \\
\hline $\boldsymbol{H I}$ & $\begin{array}{l}H I=\left(H_{\text {mean }}-H_{\min }\right) /\left(H_{\max }-H_{\min }\right) \\
H_{\text {mean }}, H_{\text {max }} \text {, and } H_{\min } \text { denote the mean, maxi- } \\
\text { mum, and minimum heights of a basin, re- } \\
\text { spectively. }\end{array}$ & $\begin{array}{l}H I>0.7,0.5 \leqslant H I \leqslant 0.7 \text {, and } H I<0.5 \text { equate to } \\
\text { high, moderate, and low levels of tectonic activity, } \\
\text { respectively (e.g., Altın, 2012; Mahmood and Glo- } \\
\text { aguen, 2012). }\end{array}$ \\
\hline $\boldsymbol{A F}$ & $\begin{array}{l}A F=100 \times(A r / A t) \\
A \mathrm{r} \text { denotes the area of the basin on the right } \\
\text { side of the trunk stream, while } A t \text { refers to the } \\
\text { total basin area. }\end{array}$ & $\begin{array}{l}|A F-50|>15,7 \leqslant|A F-50| \leqslant 15, \text { and } \mid A F- \\
50 \mid<7 \text { equate to high, moderate, and low levels of } \\
\text { tectonic activity, respectively (e.g., Hamdouni et al., } \\
\text { 2008; Gao et al., 2013). }\end{array}$ \\
\hline$S L$ & $\begin{array}{l}S L=(\Delta H / \Delta L) \times L \\
\Delta H \text { denotes the difference in elevation be- } \\
\text { tween the ends of the river reach under con- } \\
\text { sideration, while } \Delta L \text { denotes the length of the } \\
\text { reach, } L \text { is the distance between the measured } \\
\text { reach and the drainage divide. }\end{array}$ & $\begin{array}{l}S L>500,300 \leqslant S L \leqslant 500 \text {, and } S L<300 \text { equate } \\
\text { to high, moderate, and low levels of tectonic activ- } \\
\text { ity, respectively (e.g., Hamdouni et al., 2008; Gao et } \\
\text { al., 2016). }\end{array}$ \\
\hline Bs & $\begin{array}{l}B s=B 1 / B w \\
B 1 \text { denotes the basin length measured from } \\
\text { the headwater to the mouth, while } B \mathrm{w} \text { is the } \\
\text { maximum basin width. }\end{array}$ & $\begin{array}{l}\text { High, moderate, and low levels of tectonic activity } \\
\text { have values of } B \mathrm{~s}>3,2-3 \text {, and }<2 \text {, respectively } \\
\text { (e.g., Hamdouni et al., 2008; Gao et al., 2016). }\end{array}$ \\
\hline$V f$ & $\begin{array}{l}V f=2 V f w /[(E l d-E s c)+(E r d-E s c)] \\
V f w \text { denotes the width of the valley floor, } \\
\text { while Eld and Erd refer to the elevations of } \\
\text { the left and right valley divides, respectively, } \\
\text { and Esc is the elevation of the valley floor. }\end{array}$ & $\begin{array}{l}V f<1,1 \leqslant V f \leqslant 3 \text {, and } V f>3 \text { equate to high, } \\
\text { moderate, and low levels of tectonic activity, re- } \\
\text { spectively (e.g., Hamdouni et al., 2008; Altın, 2012; } \\
\text { Mahmood and Gloaguen, 2012; Gao et al., 2016). } \\
\text { For calculating } V f \text {, numerous erosional valley } \\
\text { cross-sections were obtained using the "interpolate } \\
\text { line" tool in the software ArcGIS. The horizontal } \\
\text { width between two shoulders and the width of the } \\
\text { valley bottom at a height of } 5 \mathrm{~m} \text { were measured } \\
\text { from each valley cross-section, and an average } V f \\
\text { value was calculated for each basin. }\end{array}$ \\
\hline
\end{tabular}

\subsection{Stream power}

Stream power $(S p)$, measured in W/m, was defined as follows (Summerfield, 1991):

$$
S p=\gamma \times Q \times S
$$

where $\gamma$ denotes the specific weight of water $\left(9,800 \mathrm{~N} / \mathrm{m}^{3}\right), s$ is the slope of the water surface (generally approximated as the channel bed slope), and $Q$ is water discharge $\left(\mathrm{m}^{3} / \mathrm{s}\right)$. The stream power of a river determines sediment transport capacity and is therefore fundamental to longitudinal profile development; in other words, a greater stream power equates to a higher transport capacity, and thus a longitudinal profile that is more vulnerable to down-cutting. This feature can be clearly described via a stream power gradient (SPG); when the SPG is greater than zero, power increases along the profile, and thus eroding and delivering more sediment downstream and increasing concavity. In contrast, power decreases downstream when the SPG is less than zero, the energy needed to transport sediments is inadequate and deposition occurs. In order to compute SPG along the mainstream, stream discharge along the channel was calculated as follows:

$$
\left\{\begin{array}{l}
Q_{1}=c \times A_{1} \times q_{1} \\
Q_{i}=c \times\left(A_{i}-A_{i-1}\right) \times q_{i}+Q_{i-1}
\end{array}\right.
$$


where $Q_{1}, A_{1}$, and $q_{1}$ refer to discharge, confluence area, and annual rainfall adjacent to the river source, respectively, while $Q_{i}$ and $q_{i}$ denote the discharge and rainfall at point $i$, respectively, $\left(A_{i}-A_{i-1}\right) \times q_{i}$ is the discharge generated by the added confluence areas at point $i$, $Q_{i-1}$ is the discharge at point $i-1$, and $c$ is the runoff coefficient. In this case, as three hydrological stations are present within the study area and the lithologies of kongdui basins are all nearly identical, all runoff coefficients are also almost the same. We therefore used the value 0.02 in this study in all cases as this corresponds with the ratio of measured discharge to precipitation within the HTC, XLG, and MBL basins.

\subsection{Coupling between concavity, tectonic activity, and stream power}

The morphologic characteristics of longitudinal profiles are related to both internal and external forces. We therefore utilized $C I, I_{\text {at }}$, and $S p$ as proxy indicators in this analysis to describe the morphological features of profiles, basin tectonic activity, and river action, respectively. In this context, $C I$ values denote the long-term effects of tectonic and river activities, so their historic averages should be used. The $I_{\text {at }}$ values calculated based on geomorphic parameters of modern topography can be directly used as proxies for the approximate average intensities of past tectonic activity. Assuming an existing river profile has been developed from an initial linear profile as shown in Figure 4, historic average river power can be approximately expressed as follows:

$$
S p_{\text {mean }} \approx \frac{(S p l-e)+S p}{2}
$$

where $S p l$ denotes average stream power under present climatic conditions of the original straight longitudinal profile not subject to later tectonic uplift, $S p$ is the average stream power calculated for modern climatic and topographic conditions, and $e$ denotes the change in average stream power caused by climate change, tectonic uplift, and watershed expansion over the course of basin evolution (Figure 4). In this case, as the duration of the dry-cold period was generally about 2.6 times that of the warm period and continual tectonic uplift is known to have occurred throughout the Quaternary (Deng et al., 1999; Yue et al., 2007), the $e$ value must be considerably

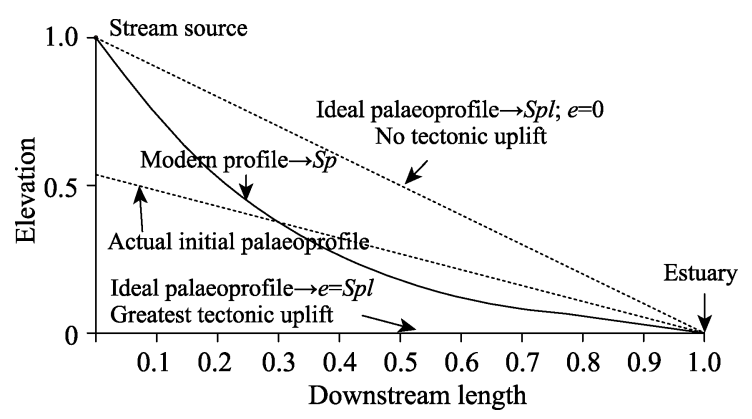

Figure 4 Modern and three hypothetical original profiles for a stream. We assume that the highest profile will remain steady while the other two initial examples will be elevated to the highest extent by later tectonic uplift in the absence of erosion lower than Spl. Further, as the $C I$ value of a small-scale longitudinal profile is larger than that of a large-scale longitudinal profile under the same stream power conditions, a binary regression model with the scale influence eliminated can be established, as follows:

$$
C I=a \times I_{\text {at }}+b \times S P_{\text {mean }}+c
$$

where $a$ and $b$ are the regression coefficients, $S P_{\text {mean }}=S p_{\text {mean }} / L, L$ is stream length, and $c$ is a constant. Prior to establishing a model, values for both $I_{\text {at }}$ and $S P_{\text {mean }}$ were normalized to eliminate any differences due to the indicator unit as well as to make it simpler to deter- 
mine the significance of tectonic activity and river action on longitudinal profiles. This latter step was accomplished by comparing the magnitudes of $|a|$ and $|b|$.

\section{Results and discussion}

\subsection{The concavity of longitudinal profiles}

The ten streams evaluated in this study were all generated during uplift of the same tectonic unit, and therefore have nearly the same evolutionary history (e.g., Deng et al., 1999). Nevertheless, besides spatial and temporal changes in tectonic activity and precipitation conditions, a number of parameters have varied over the course of stream evolution, including watershed area, channel length, and altitude differences (e.g., Marple et al., 1993; Whipple et al., 2000; $\mathrm{Hu}$ et al., 2010). The consequent longitudinal profiles and their sub-segments have therefore different values of concavity (e.g., Snow and Slingerland, 1987; Phillips et al., 2008; Miller et al., 2013; Pan et al., 2015). As for the ten streams under discussion, they all have a concave profile (Figure 5a) with their profile $C I$ values being greater than one and conspicuously increasing from west-to-east (Figure $5 b$ ).

(a)

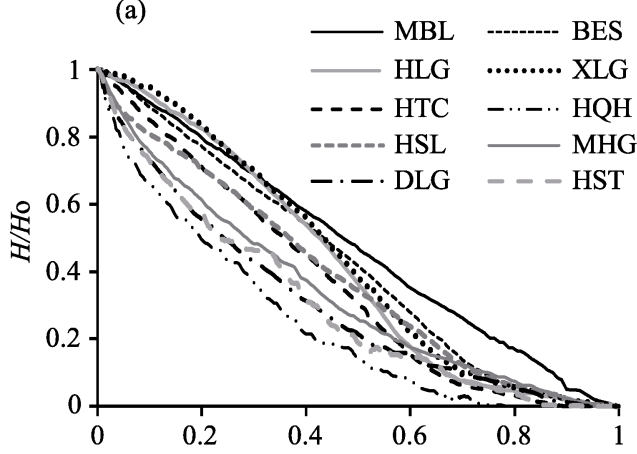

(b)

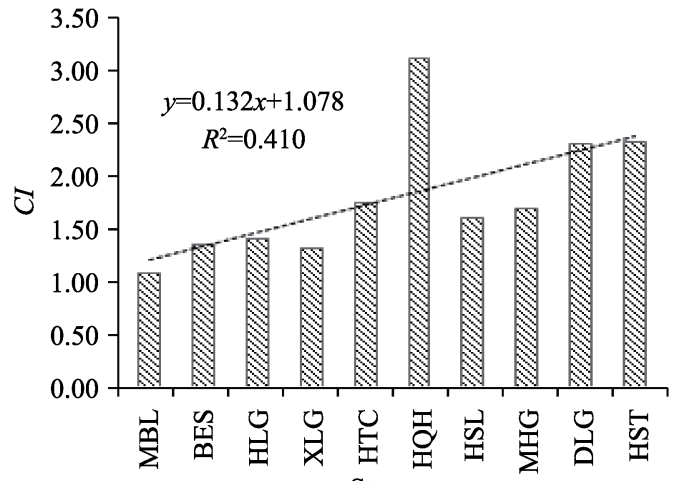

Streams

Figure 5 Longitudinal profile shapes (a) and $C I$ values (b). Abbreviations: $H / H \mathrm{o}$, ratio between height at the point of measurement above the river mouth $(H)$ and the total fall of the stream $(H o)$; $L / L o$, ratio between stream length from the river mouth to the point of measurement $(L)$ and total length $(L o)$

The data presented in Table 3 reveal significant negative correlations between $C I$ values and drainage area, as well as versus altitude differences, altitude averages, and profile lengths. Such negative correlations with landform variables are expected; in the first place, if all other conditions are held the same, a large drainage area and a long river profile length usually implies that main-stem channel within a basin has experienced a high degree of erosion. Further, a larger difference in altitude within a basin is also associated with a high rate of uplift and the average altitude of a longitudinal profile reflects integrated features of both erosion and tectonic uplift; thus, a higher average altitude implies faster historic tectonic uplift and/or a slower erosion rate. We therefore conclude that negative $C I$ correlations with respect to these four landform variables indicate that channel erosion has significantly persisted within all ten kongduis. Data also show that $C I$ is negatively correlated with sediment yield; this demonstrates that sediment yield decreases as the concavity of longitudinal profiles increases. 
Table 3 Correlation coefficients between landform elements within the ten kongdui basins

\begin{tabular}{|c|c|c|c|c|c|c|}
\hline & $\begin{array}{l}\text { Profile } \\
\text { length }\end{array}$ & $\begin{array}{c}\text { Altitude } \\
\text { difference }\end{array}$ & $\begin{array}{l}\text { Average } \\
\text { altitude }\end{array}$ & $\begin{array}{c}\text { Drainage } \\
\text { area }\end{array}$ & Concavity & $\begin{array}{c}\text { Sediment } \\
\text { yield }\end{array}$ \\
\hline Profile length & 1 & $0.674 *$ & $0.730 *$ & $0.964 * *$ & $-0.844 * *$ & $0.854 * *$ \\
\hline Altitude difference & & 1 & $0.961 *$ & 0.592 & $-0.869 * *$ & 0.366 \\
\hline Average altitude & & & 1 & $0.701 *$ & $-0.887 * *$ & 0.437 \\
\hline Drainage area & & & & 1 & $-0.781 * *$ & $0.897 * *$ \\
\hline Concavity & & & & & 1 & $-0.639 *$ \\
\hline Sediment yield & & & & & & 1 \\
\hline
\end{tabular}

* significant at $\alpha=0.05 ; * *$ significant at $\alpha=0.01$

In order to further analyze the characteristics of concavity value variation along each longitudinal profile, we calculated individual values for segments at certain points in each case. We used a segment length of $15 \mathrm{~km}$ in this analysis because correlations between $C I$ values of whole profiles and corresponding average values for segments become less significant below this cut-off distance (Figure 6). Our use of lengths greater than $15 \mathrm{~km}$ may therefore mean that the overall segment $C I$ values are indicative of the physical mechanisms for forming the entire profile; indeed, data

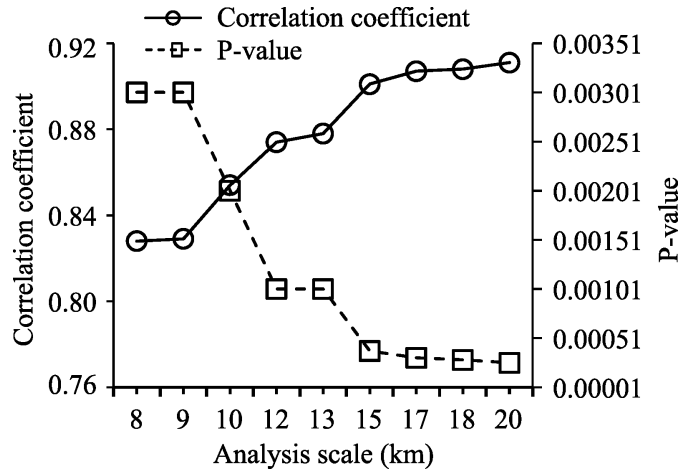

Figure 6 Changes in coefficients and P-values (significance) of correlations between profile $C I$ values and segment averages as segment length increases show that the highest $C I$ value for each longitudinal profile generally occurs within its lower reaches while values for middle and upper sections tend to fluctuate around one (Figure 7). The higher $C I$ values in the lower reaches of these kongduis are favorable for sediment deposition, while the lower $C I$ values in the middle and upper reaches promote sediment delivery.

\subsection{The intensity of tectonic activity}

The basements of all the river basins considered in this study comprise parts of the western North China Craton (e.g., Wang et al., 2010; Zhang et al., 2011). Thus, as a result of Ordos Block-associated tectonic activity, the upstream regions of all basins have also undergone several cycles of subsidence and uplift over the course of their geologic history (e.g., Deng et al., 1999; Zheng et al., 2006; Yue et al., 2007) within mainly a terrestrial environment (Wang, 1985). The basic features of the current landscape of the basins were formed via uplift of the Ordos Block and subsidence of Hetao Basin during the Cenozoic (Deng et al., 1999). Although movement of the Ordos Block has been dominated by vertical uplift, the intensity of tectonic activity within the basins evaluated here remains unclear. Current results reveal a range of $I_{\text {RAT }}$ values between 2.2 and 3, implying that moderate-to-weak intensity tectonic activities have occurred within these basins (Table 4). Amongst them, western ones (i.e., the MBL, BES, HLG, XLG, and HTC) are characterized by relatively stronger intensities of tectonic activity compared to their eastern counterparts (Figure 8a). Tectonic activity within the basins is usually manifested in a variety of ways including uplift, subsidence, and dislocation (e.g., Font et al., 2010; Mahmood and Gloaguen, 2012); 

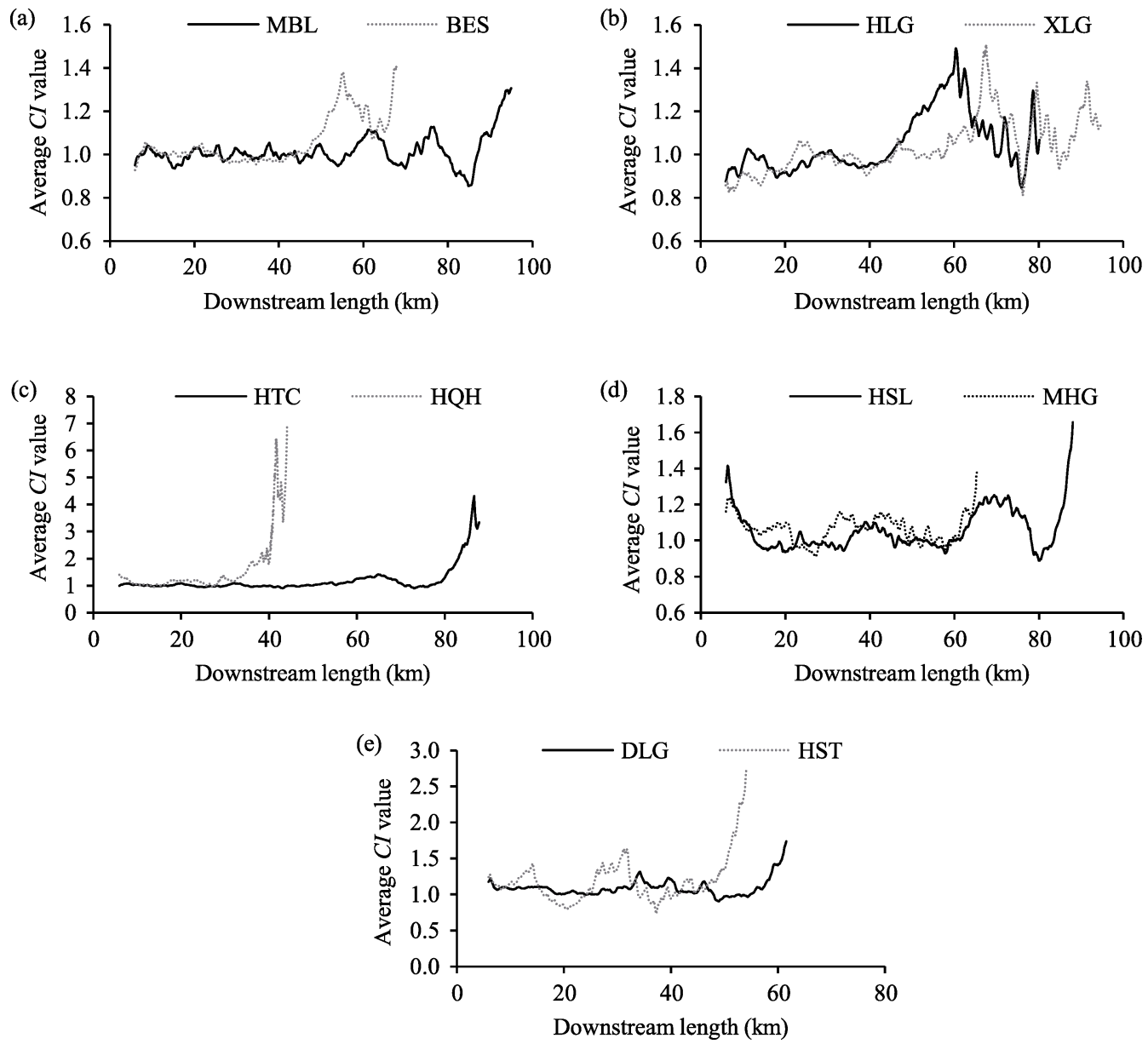

Figure 7 Variation in $C I$ values of $15-\mathrm{km}$ long segments along the longitudinal profiles

Table 4 Geomorphic indexes and values for the intensity of tectonic activity within the ten kongdui basins evaluated in this study

\begin{tabular}{|c|c|c|c|c|c|c|c|c|c|c|c|c|c|}
\hline \multirow{2}{*}{ Basins } & \multirow{2}{*}{$H I$} & \multirow{2}{*}{$A F$} & \multirow{2}{*}{$S L$} & \multirow{2}{*}{$B s$} & \multirow{2}{*}{$V f$} & \multirow{2}{*}{$I_{\mathrm{RAT}}$} & \multicolumn{5}{|c|}{ Geomorphic index class } & \multirow{2}{*}{$\begin{array}{l}I_{\mathrm{RAT}} \\
\text { class }\end{array}$} & \multirow{2}{*}{ Intensity } \\
\hline & & & & & & & $H I$ & $A F$ & $S L$ & Bs & $V f$ & & \\
\hline MBL & 0.55 & 61.76 & 245.56 & 3.77 & 6.49 & 2.2 & 2 & 2 & 3 & 1 & 3 & 3 & Moderate \\
\hline BES & 0.51 & 21.92 & 286.97 & 2.73 & 6.51 & 2.2 & 2 & 1 & 3 & 2 & 3 & 3 & Moderate \\
\hline HLG & 0.54 & 45.52 & 250.92 & 3.08 & 8.37 & 2.4 & 2 & 3 & 3 & 1 & 3 & 3 & Moderate \\
\hline XLG & 0.60 & 63.58 & 222.36 & 2.70 & 6.57 & 2.4 & 2 & 2 & 3 & 2 & 3 & 3 & Moderate \\
\hline HTC & 0.63 & 56.70 & 224.94 & 3.50 & 5.67 & 2.4 & 2 & 3 & 3 & 1 & 3 & 3 & Moderate \\
\hline $\mathrm{HQH}$ & 0.31 & 55.54 & 100.96 & 1.75 & 4.85 & 3 & 3 & 3 & 3 & 3 & 3 & 4 & Weak \\
\hline HSL & 0.52 & 47.89 & 177.22 & 2.60 & 5.77 & 2.8 & 2 & 3 & 3 & 3 & 3 & 4 & Weak \\
\hline MHG & 0.41 & 48.94 & 153.84 & 4.23 & 6.15 & 2.6 & 3 & 3 & 3 & 1 & 3 & 4 & Weak \\
\hline DLG & 0.41 & 54.59 & 128.57 & 3.28 & 7.09 & 2.6 & 3 & 3 & 3 & 1 & 3 & 4 & Weak \\
\hline HST & 0.50 & 38.83 & 119.75 & 1.24 & 5.30 & 2.6 & 2 & 2 & 3 & 3 & 3 & 4 & Weak \\
\hline
\end{tabular}

the first two of these can be recorded via longitudinal profile deformation. A large amount of previous work has shown that a higher Hack profile bulge corresponds with faster tectonic uplift (e.g., Hack, 1973; Merritts, 1989; Rhea, 1989; Chen et al., 2003; Brookfield, 2008), and that the shape of such profiles (Figure $8 \mathrm{~b}$ ) reflects the rate of uplift. It is note- 
worthy that the lower concave segments of kongdui Hack profiles usually occur at altitudes below 1,050 $\mathrm{m}$ (Figure $8 \mathrm{~b}$ ), indicative of structural subsidence.
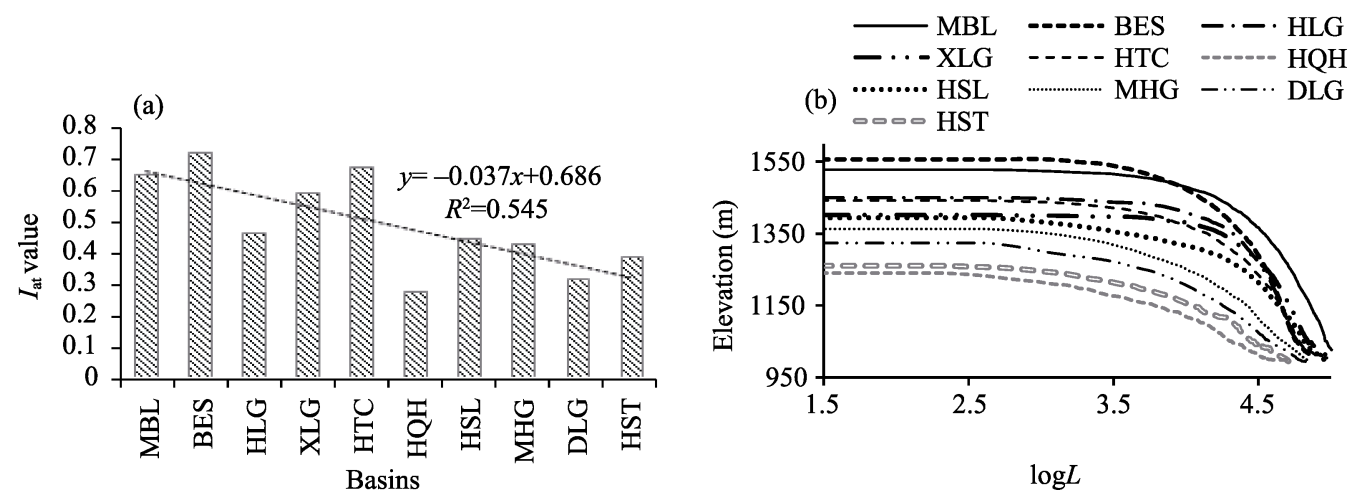

Figure 8 The intensity of tectonic activity (a) and Hack profiles for the ten kongdui basins evaluated in this study (b)

\subsection{Stream power characteristics}

The magnitude of stream power directly influences fluvial erosion and sediment transport capacities. Thus, the greater the power, the more the sediments can be transported by runoff (Whipple et al., 1999; 2000). The data assembled here (Figure 9) reveal significant spatial variations in stream power along the ten streams, with higher values generally found within middle reaches. This is because the upper parts of river basins comprise the main drainage areas for the ten kongduis, and so water discharge peaks within middle reaches; this corresponds with the fact that the ability of a river to erode sand rises to a maximum within middle reaches, clearly visible in the XLG, HTC, HLG, and HSL examples. At the same time, a downstream reduction in stream power is also seen markedly within the lower reaches of the streams considered here and might be a key factor underlying sediment deposition and the formation of alluvial fans. In this context, the MBL is unusual because stream power predominantly increases overall downstream into the estuary; it is therefore possible that the sediment load in this case also gradually increases downstream, and so the volume of sediments deposited within lower reaches is less than seen in its counterparts. This phenomenon is reflected distinctly by the SPG (Figure 9); this gradient is generally higher than zero within the upper reaches of most streams and below this value only in lower section. Indeed, the SPG of some streams switches to negative values within their middle reaches, indicating regions that are most prone to sediment deposition (i.e., the HLG, XLG, HTC, and MHG). Average SPG values for some profiles remain higher than zero, however (i.e., the MBL, BES, HLG, XLG, and MHG), and these streams are therefore subject to overall channel erosion (Figure 10a). The length of the erosional section is larger than the depositional in most profiles (Figure 10b), while channel erosion of streams in the central part of the study area tends to be more active than in eastern and western cases, in concert with average power (Figure 10a). The most actively eroded stream within the study area is the XLG while the least active is the $\mathrm{HQH}$; the former consequently is also characterized by the highest sediment discharge while the latter has the lowest (Table 1).

\subsection{Coupled characteristics of profiles and internal-external forces}

The nature of each longitudinal profile can be viewed as a function of stream action, lithology, 

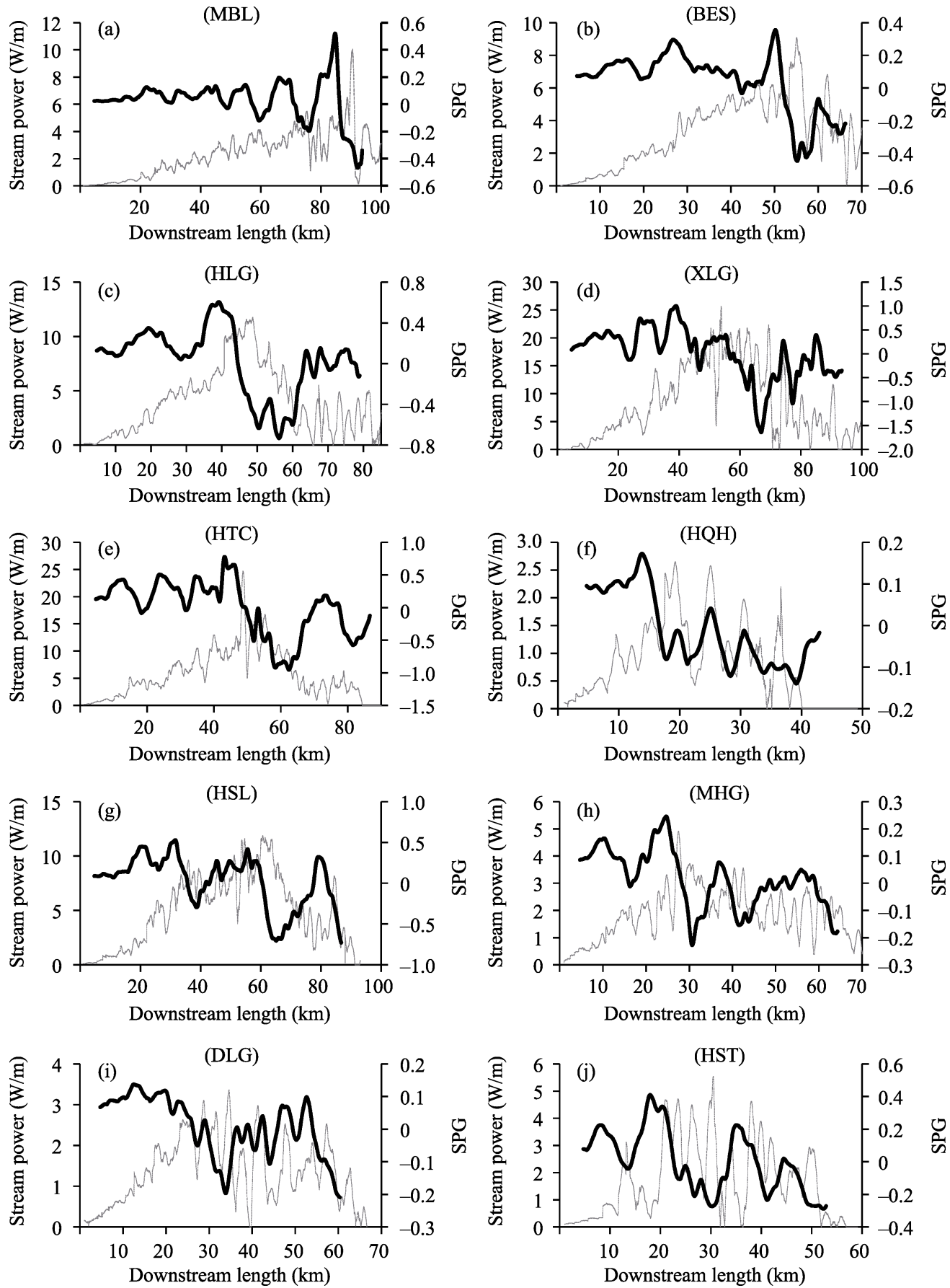

Figure 9 Stream power and SPG variations over a fixed 10-km distance in streams across the study area. The gray line denotes stream power while the black one indicates SPG.

and tectonic activity (Hu et al., 2010; Gallen and Wegmann et al., 2017). Thus, as the ten kongdui basins discussed here have nearly the same underlying substrates, two binary regression models were established based on $C I$ values of their longitudinal profiles as well as average stream power and $I_{\text {at }}$ values that were used as proxies for the intensity of tectonic activity (Figure 11a). These models enabled us to determine the dynamic mechanisms that 


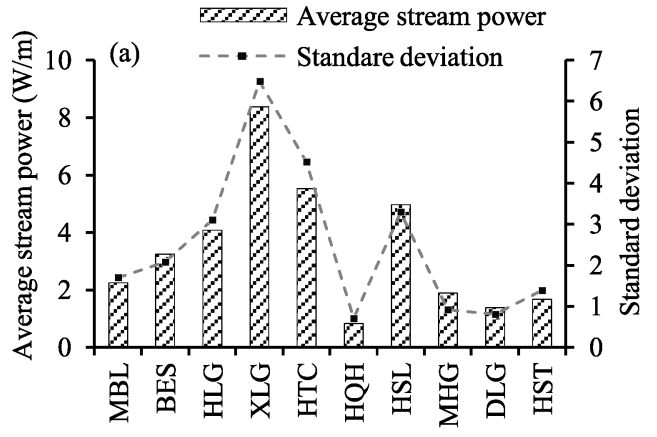

Streams

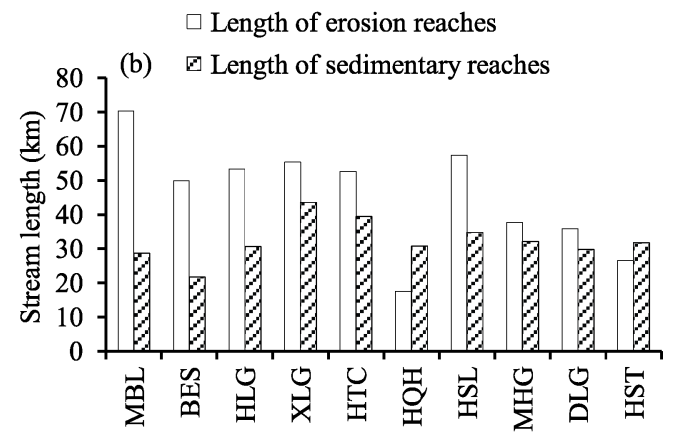

Streams

Figure 10 Average stream power values (a) and the lengths of erosional and depositional reaches (b)

have influenced stream longitudinal profiles under two extreme conditions. Results reveal that simulated concavity values derived from both regression models are similar to actual numbers (Figure 11b); indeed, both regression coefficients and P-values highlight the fact that profile morphological features have all been markedly affected by tectonic activity (Table 5).
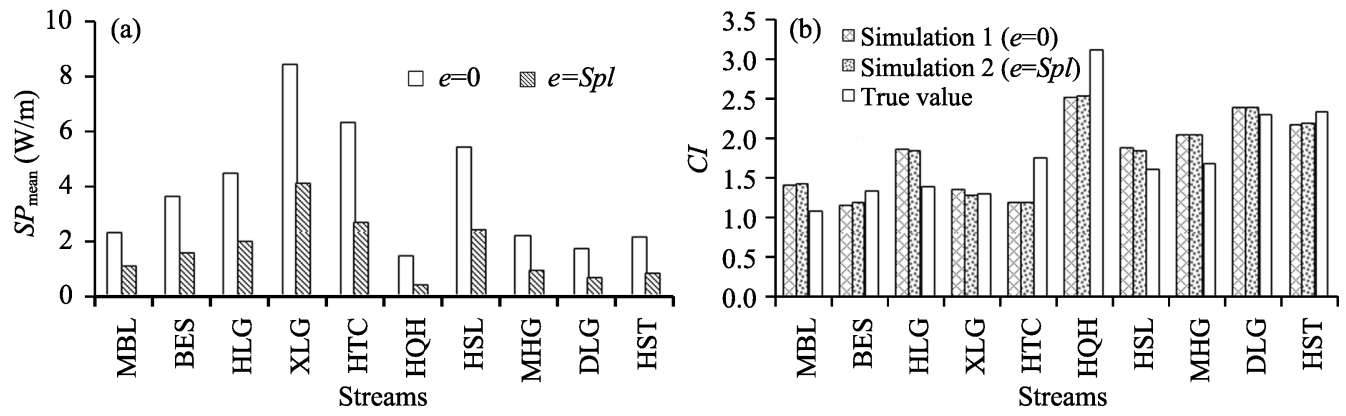

Figure 11 Average values of stream power (a) and simulated concavity (b)

Table 5 Relations between profile concavity and internal-external forces

\begin{tabular}{|c|c|c|c|c|c|}
\hline $\begin{array}{c}\text { Extreme } \\
\text { case }\end{array}$ & Natural conditions & Regression model & Factor P-value & $\begin{array}{c}\text { Equation } \\
\text { P-value }\end{array}$ & $\mathrm{R}^{2}$ \\
\hline$e=0$ & $\begin{array}{l}\text { Elevation of the stream } \\
\text { source is constant and } \\
\text { water discharge has re- } \\
\text { mained the same. }\end{array}$ & $C I=-1.38 \times I_{\text {at }}-0.07 \times S P_{\text {mean }}+2.51$ & $\begin{array}{c}I_{\text {at }}: 0.0226 \\
S P_{\text {mean }}: 0.8980\end{array}$ & 0.0333 & 0.62 \\
\hline$e=S p l$ & $\begin{array}{l}\text { The difference in height } \\
\text { between the stream source } \\
\text { and the estuary is zero. }\end{array}$ & $C I=-1.26 \times I_{\text {at }}-0.30 \times S P_{\text {mean }}+2.53$ & $\begin{array}{c}I_{\text {at }}: 0.0344 \\
S P_{\text {mean }}: 0.5930\end{array}$ & 0.0288 & 0.64 \\
\hline
\end{tabular}

\section{Conclusions}

The results presented in this study lead to a number of clear conclusions for the ten kongduis. These are founded on analyses of longitudinal profile concavity values, stream power, the intensity of tectonic activity, and the relationships between $C I$ values and internal-external forces.

In the first place, the data presented here show that the longitudinal profiles of the ten kongduis are all concave up and have $C I$ values in the range between 1.1-3.1, increasing from west-to-east. $C I$ values for longitudinal profiles are significantly negatively correlated 
with profile length, altitude difference and average as well as drainage area and sediment yield. The negative relationship seen between the $C I$ values of longitudinal profiles and sediment yield within kongduis implies that the latter decreases as concavity increases, and that sediment transport within eastern streams has been hindered markedly. This latter conclusion is clear from the higher $C I$ values seen in eastern kongduis compared to their western counterparts. The largest values of segment concavity are seen in the lower reaches of each longitudinal profile and so sediment transport capacity is also reduced within these reaches.

Second, our data show that all ten kongdui basins have experienced both moderate and weak tectonic activities over time, and that intensity has weakened from west-to-east but the lowest is seen in the HQH. It is also noteworthy that the influence of tectonic activities on longitudinal profiles is mainly manifested as tectonic uplift.

Third, the results of this study reveal that stream power varies greatly along channels but peaks within the middle reaches of all kongduis, with the exception of the MBL. A conspicuous downstream reduction in stream power within the lower reaches of all kongduis is also marked in our data and is considered to be the main reason underlying sediment deposition and alluvial fan formation. Average stream power values range between $0.8 \mathrm{~W} / \mathrm{m}$ and $8.4 \mathrm{~W} / \mathrm{m}$; overall, average stream power values for western kongduis tend to be higher than those for the eastern ones. We have also been able to show that river channel erosion in western and central basins is more active than in eastern examples.

Fourth, data show that kongdui longitudinal profile concavity values have mainly been affected by tectonic uplift over time and that the influence of river action has been insignificant.

\section{References}

Altın T B, 2012. Geomorphic signatures of active tectonic in drainage basins in the southern Bolkar Mountains, Turkey. Journal of the Indian Society of Remote Sensing, 40(2): 271-285.

Ambili V, Narayana A C, 2014. Tectonic effects on the longitudinal profiles of the Chaliyar River and its tributaries, southwest India. Geomorphology, 217(2): 37-47.

Bergonse R, Reis E, 2015. Reconstructing pre-erosion topography using spatial interpolation techniques: A validation-based approach. Journal of Geographical Sciences, 25(2): 196-210.

Brookfield M E, 2008. The evolution of the great river systems of southern Asia during the Cenozoic India-Asia collision: Rivers draining north from the Pamir syntaxis. Geomorphology, 22(3/4): 285-312.

Chen Y C, Sung Q C, Cheng K Y, 2003. Along strike variations of morphotectonic features in the western foothills of Taiwan: Tectonic implications based on stream-gradient and hypsometric analysis. Geomorphology, 22(1/2): 109-137.

Deng Q D, Cheng S P, Min W et al., 1999. Discussion on Cenozoic tectonics and dynamics of the Ordos Block. Journal of Geomechanics, 5(3): 13-19. (in Chinese)

Dušan B, Ján B, Daniel K et al., 2017. Morphometric and geological conditions for sediment accumulation in the Udava River, Outer Carpathians, Slovakia. Journal of Geographical Sciences, 27(8): 981-998.

Font M, Amorese D, Lagarde J L, 2010. DEM and GIS analysis of the stream gradient index to evaluate effects of tectonics: The Normandy intraplate area (NW France). Geomorphology, 119(3):172-180.

Gallen S F, Wegmann K W, 2017. River profile response to normal fault growth and linkage: An example from the Hellenic forearc of south-central Crete, Greece. Earth Surface Dynamics, 5(1): 1-47.

Gao M, Zeilinger G, Xu X et al., 2016. Active tectonics evaluation from geomorphic indices for the central and the southern Longmenshan range on the Eastern Tibetan Plateau, China. Tectonics, 35: 1812-1826.

Hack J T, 1973. Stream-profile analysis and stream-gradient index. Journal of Research of the U.S. Geological Survey, 1: 421-429.

Hamdouni R E, Irigaray C, Fernández T et al., 2008. Assessment of relative active tectonics, southwest border of Sierra Nevada (Southern Spain). Geomorphology, 96: 150-173.

Hu X F, Pan B T, Kirby E et al., 2010. Spatial differences in rock uplift rates inferred from channel steepness indices along the northern flank of the Qilian Mountain, northeast Tibetan Plateau. Chinese Science Bulletin, 55(27/28): 3205-3214.

Hu X F, Pan B T, Li Q, 2014. Principles of the stream power erosion model and the latest progress in research. 
Journal of Lanzhou University (Natural Sciences), 50(6): 824-831. (in Chinese)

Jiang Z X, 1987. Model of development and rule of evolution of the longitudinal profiles of the valley of the Three Rivers in the northwestern part of Yunnan Province. Acta Geographica Sinica, 42(1): 16-26. (in Chinese)

Langbein W B, 1964. Profiles of rivers of uniform discharge. United States Geological Survey Professional Paper, 501B: 119-122.

Lin X Z, Guo Y, Hou S Z, 2014. Estimation of sediment discharge of ten tributaries of the Yellow River in Inner Mongolia. Journal of Sediment Research, 2: 15-20. (in Chinese)

Mahmood S A, Gloaguen R, 2012. Appraisal of active tectonics in Hindu Kush: Insights from DEM derived geomorphic indices and drainage analysis. Geoscience Frontiers, 3(4): 407.

Marple R T, Talwani P, 1993. Evidence of possible tectonic unwarping along the South Carolina coastal plain from an examination of river morphology and elevation data. Geology, 21(7): 651-654.

Merritts D, Vincent K R, 1989. Geomorphic response of coastal streams to low, intermediate, and high rates of uplift, Mendocino triple junction region, northern California. Geological Society of America Bulletin, 110(11): 1373-1388.

Miller S R, Sak P B, Kirby E et al., 2013. Neogene rejuvenation of central Appalachian topography: Evidence for differential rock uplift from stream profiles and erosion rates. Earth \& Planetary Sciences Letters, 369(3): $1-12$.

Ohmori H, 1991. Change in the mathematical function type describing the longitudinal profile of a river through an evolutionary process. Journal of Geology, 99: 97-110.

Owono F M, Ntamak-Nida M J, Dauteuil O et al., 2016. Morphology and long-term landscape evolution of the South African plateau in South Namibia. Catena, 142: 47-65.

Pan B T, Li Q, Hu X F et al., 2015. Bedrock channels response to differential rock uplift in eastern Qilian Mountain along the northeastern margin of the Tibetan Plateau. Journal of Asian Earth Sciences, 100: 1-19.

Pérez-Peña J V, Azañón J M, Azor A et al., 2010. Spatial analysis of stream power using GIS: SLk anomaly maps. Earth Surface Processes \& Landforms, 34(1): 16-25.

Phillips J D, Lutz J D, 2008. Profile convexities in bedrock and alluvial streams. Geomorphology, 102(3): 554-566.

Pipaud I, Loibl D, Lehmkuhl F, 2015. Evaluation of TanDEM-X elevation data for geomorphological mapping and interpretation in high mountain environments: A case study from SE Tibet, China. Geomorphology, 246: 232-254.

Rãdoane M, Rãdoane N, Dan D, 2003. Geomorphological evolution of longitudinal river profiles in the Carpathians. Geomorphology, 50(4): 293-306.

Rhea S, 1989. Evidence of uplift near Charleston, South Carolina. Geology, 17(4): 311-315.

Snow R S, Slingerland R L, 1987. Mathematical modeling of graded river profiles. Journal of Geology, 95(1): 15-33.

Summerfield M A, 1991. Global Geomorphology. Longman: Singapore.

Wang H Z, 1985. Atlas of the Palaeo-Geography of China. Beijing: Sinomap Press. (in Chinese)

Wang Q S, Teng J W, An Y L et al., 2010. Gravity field and deep crustal structures of the Yinshan Orogen and the northern Ordos Basin. Progress in Geophysics, 25(5): 1590-1598. (in Chinese)

Whipple K X, Hancock G S, Anderson R S, 2000. River incision into bedrock: Mechanics and relative efficacy of plucking, abrasion, and cavitation. Geological Society of America Bulletin, 112(3): 490-503.

Whipple K X, Tucker G E, 1999. Dynamics of the stream power river incision model: Implications for height limits of mountain ranges, landscape response timescales, and research needs. Journal of Geophysical Research, 104(B8): 17661-17674.

Xu J X, 2013. Erosion and sediment yield of ten small tributaries joining Inner Mongolia reach of upper Yellow River in relation to coupled wind-water processes and hyper-concentrated flows. Journal of Sediment Research, (6): 27-36. (in Chinese)

$\mathrm{Xu} \mathrm{J}$ X, 2014. Temporal and spatial variations in erosion and sediment yield and the cause in the ten small tributaries to the Inner Mongolia Reach of the Yellow River. Journal of Desert Research, 34(6): 1641-1649. (in Chinese)

Yang M, Li L, Zhou J et al., 2015. Mesozoic structural evolution of the Hangjinqi area in the northern Ordos Basin, North China. Marine and Petroleum Geology, 66: 695-710.

Yao H, Shi C, Shao W, 2016. Changes and influencing factors of the sediment load in the Xiliugou basin of the upper Yellow River, China. Catena, 142: 1-10.

Yu H Y, Luo L, Ma H H et al., 2017. Application appraisal in catchment hydrological analysis based on SRTM 1 Arc-second DEM. Remote Sensing for Land \& Resources, 29(2): 138-143. (in Chinese)

Yue L P, Li J X, Zheng G Z et al., 2007. Evolution of the Ordos Plateau and environmental effects. Science in China (Series D: Earth Sciences), 50(Suppl.2): 19-26.

Zhang Y Q, Teng J W, Wang F Y et al., 2011. Structure of the seismic wave property and lithology deduction of the upper crust beneath the Yinshan orogenic belt and the northern Ordos Block. Chinese Journal of Geophysics, 54(1): 87-97. (in Chinese)

Zhao G H, Li Y, Yan Z K et al., 2014. Tectonic geomorphology analysis of piedmont rivers in the middle MT. Longmenshan based on Hack profile and hypsometric integral. Quaternary Sciences, 34(2): 302-310. (in Chinese)

Zheng M L, Jin Z J, Wang Y et al., 2006. Structural characteristics and evolution of the North Ordos Basin in Late Mesozoic and Cenozoic. Journal of Earth Sciences and Environment, 28(3): 31-36. (in Chinese) 